\title{
MANAGEMENT OF CUBITUS VARUS DEFORMITY BY LATERAL CLOSING WEDGE OSTEOTOMY - A CASE SERIES
}

\author{
Murugasarathy Sambandam¹, Kalaiyarasan Thamizharasan², Duraisamy Ezhilmaran³, Maharajothi Paramasivam4
}

${ }_{1}^{1}$ Professor, Department of Orthopaedics, Chengalpattu Medical College Hospital.

${ }^{2}$ Assistant Professor, Department of Orthopaedics, Chengalpattu Medical College Hospital.

${ }^{3}$ Assistant Professor, Department of Orthopaedics, Chengalpattu Medical College Hospital.

${ }^{4}$ Assistant Professor, Department of Orthopaedics, Chengalpattu Medical College Hospital.

\section{ABSTRACT}

\section{BACKGROUND}

Lateral closing wedge osteotomy is a commonly accepted correction method for cubitus varus deformity. To fix the osteotomy many techniques are used, of which we used plating in our prospective study.

\section{MATERIALS AND METHODS}

Ten cases of cubitus varus deformity following supracondylar fracture of humerus treated by native splinting were operated by lateral closing wedge osteotomy fixed with plate between May 2016 and December 2016.

\section{RESULTS}

The mean followup period was 12 months. The results were analysed using Bellmore's criteria. Out of 10 cases, 7 had excellent results, 3 had good results.

\section{CONCLUSION}

The osteotomy fixed with plate provides more stability and early mobilisation.

\section{KEYWORDS}

Cubitus Varus Deformity, Lateral Closing Wedge Osteotomy.

HOW TO CITE THIS ARTICLE: Sambandam M, Thamizharasan K, Ezhilmaran D, et al. Management of cubitus varus deformity by lateral closing wedge osteotomy- a case series. J. Evolution Med. Dent. Sci. 2017;6(27):2275-2277, DOI: $10.14260 /$ Jemds/2017/489

\section{BACKGROUND}

Cubitus varus deformity is a common long-term complication of supracondylar fracture. Although, the deformity is unsightly, function is not affected. The cubitus varus deformity changes the elbow biomechanics, which may cause posterolateral instability. There have been many types of osteotomy proposed to correct this deformity including lateral closing wedge osteotomy, medial open wedge osteotomy, dome osteotomy, modified French osteotomy, Kims step-cut osteotomy.

Previous studies used different fixation techniques in the same method of osteotomy. Stabilisation using plate and screws increase stability lead to better fracture healing, early mobilisation and lesser chance of elbow stiffness.

This study was designed to evaluate the functional outcome of lateral closing wedge osteotomy for cubitus osteotomy, which is fixed with plate.

\section{MATERIALS AND METHODS}

In our study, we had ten patients with cubitus varus deformity who were treated with lateral closing wedge osteotomy fixed with posterior plating between May 2015

Financial or Other, Competing Interest: None.

Submission 19-02-2017, Peer Review 15-03-2017,

Acceptance 21-03-2017, Published 03-04-2017.

Corresponding Author:

Dr. Murugasarathy Sambandam,

Department of Orthopaedics,

Chengalpattu Medical College Hospital,

Chengalpattu, Kanchipuram District, Tamilnadu.

E-mail: s.murugasarathy@gmail.com, artsking2003@gmail.com

DOI: $10.14260 /$ jemds $/ 2017 / 489$

\section{(c) $($ ) $\$$}

and December 2015. All patients acquired deformity due to malunion of supracondylar fracture humerus treated by native splinting; all the patients demanded surgery for cosmetic reasons; no one had functional problems. Preoperatively, all the patients were examined preoperatively for range of movements, rotational deformity, carrying angle, lateral condyle prominence index. Preoperative anteroposterior and lateral radiographs of both elbow taken for each patient with elbow in extension and forearm in supination. Preoperative carrying angle has been measured on anteroposterior radiograph using humeroulnar angle (it is the line drawn along long axis of humerus and ulna). It is the most accurate method of measuring carrying angle as mentioned by Oppenheim et al.(1) The amount of deformity was obtained and amount of deformity to be corrected was calculated by adding carrying angle of normal side with deformity of affected side. Base of wedge was calculated based on the amount of deformity.

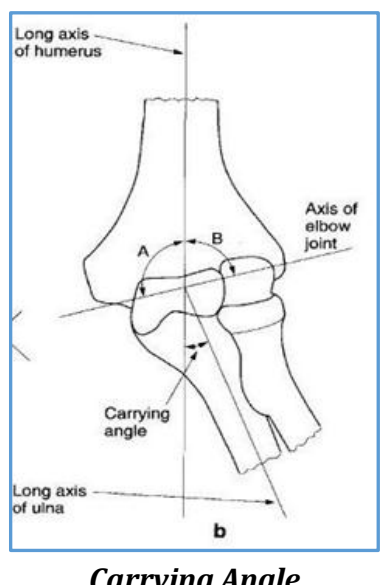

Carrying Angle 


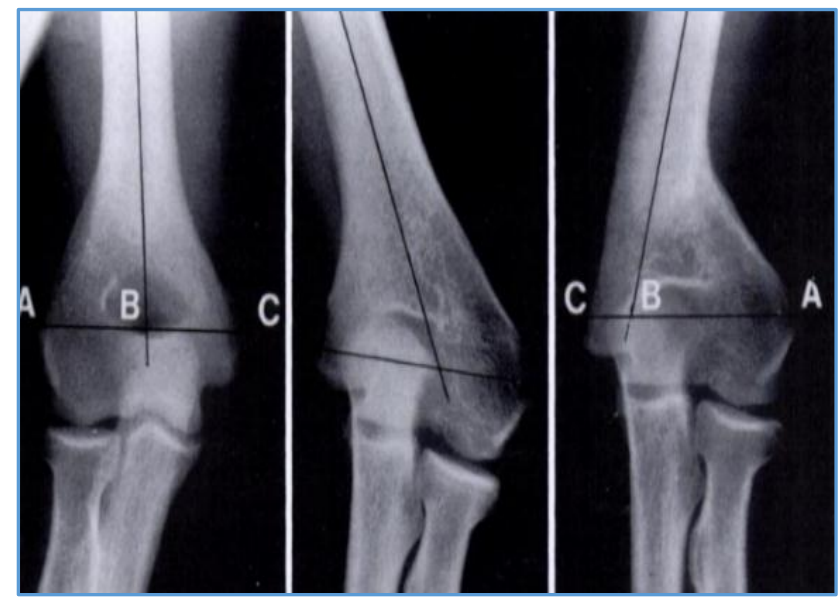

Lateral Condylar Prominence Index $(L C P I)=(A B-B C) \times 100 / A C$

\section{Surgical Techniques}

All surgeries were performed under general anaesthesia. The humerus was approached through posterior midline incision, ulnar nerve was isolated and protected. Triceps muscle was dissected from lateral and retracted medially. Wedge was made with oscillating saw, distal part of osteotomy aligned with slight realignment to avoid lateral prominence. The osteotomy was fixed with small $\mathrm{T}$ plate and screws. Postoperatively, active range of movements started intermittently with protection of removable splint. Splint was removed in 4 weeks. No postoperative complications encountered. Suture was removed at $12^{\text {th }}$ postoperative day. In every followup x-ray was obtained; carrying, LCPI and ROM assessed. All the patients were followed up at 2, 6 and 12 weeks and then every 6 months.

\section{RESULTS}

In our study, total number of patients were 10 , among them 7 were female, 3 were male, average was 9 years; 6 cases were left sided and 4 were right sided. Preoperatively, the amount of deformity varied from 12 to 18 degrees of varus and postoperatively it was corrected to 10 to 15 degrees of valgus. We followed the Bellmore's criteria to analyse the functional outcome of the postoperative case. In our study, out of 10 cases 7 had excellent outcome, 3 had good outcome.

\begin{tabular}{|c|c|c|c|c|}
\hline Outcome & ROM & $\begin{array}{c}\text { Carrying } \\
\text { Angle }\end{array}$ & LCPI & Complications \\
\hline Excellent & $\begin{array}{c}\text { Difference } \\
<10 \\
\text { degrees }\end{array}$ & $5-6$ & No increase & None \\
\hline Pood & $\begin{array}{c}\text { Difference } \\
10-20\end{array}$ & $6-10$ & $\begin{array}{c}\text { Increase } \\
<25\end{array}$ & Minor \\
\hline $\begin{array}{c}\text { Difference } \\
>20\end{array}$ & $>10$ & $\begin{array}{c}\text { Increase } \\
>25\end{array}$ & $\begin{array}{c}\text { Residual } \\
\text { effect/revision } \\
\text { surgery }\end{array}$ \\
\hline \multicolumn{5}{|c|}{ Bellmore's Criteria(2) } \\
\hline
\end{tabular}

CASE 1

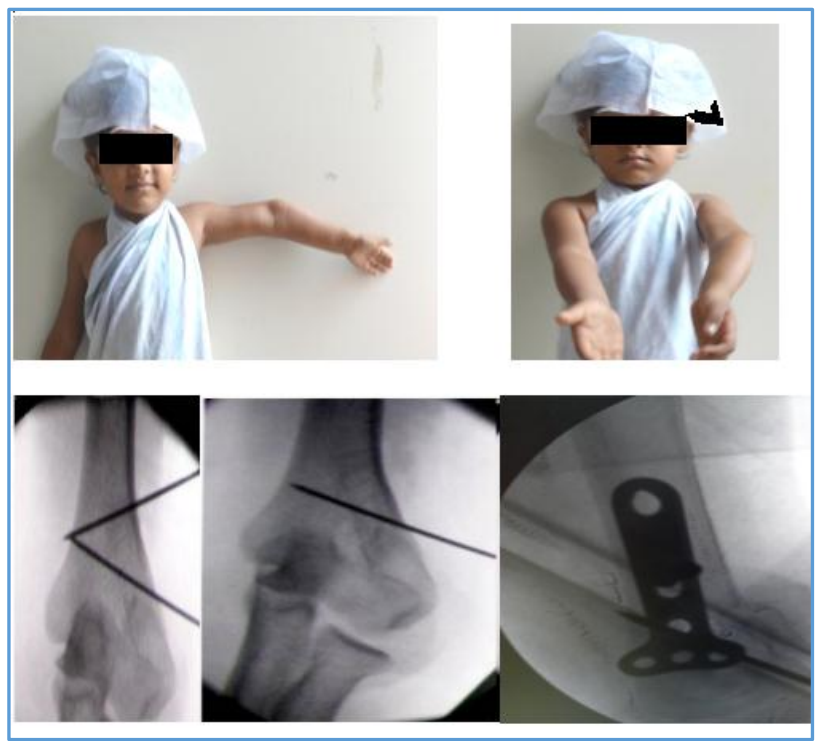

Follow-Up

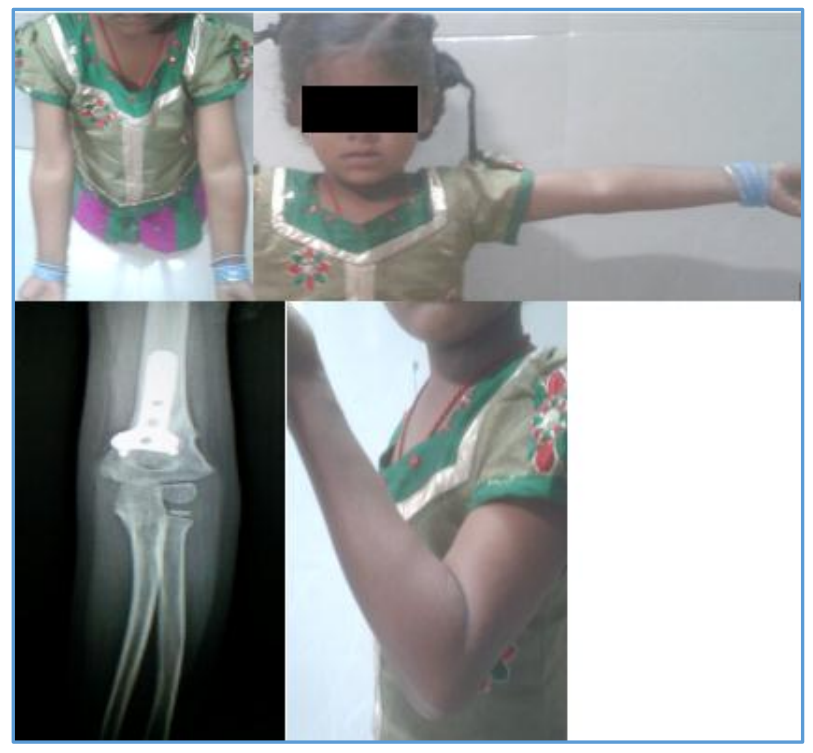

CASE 2

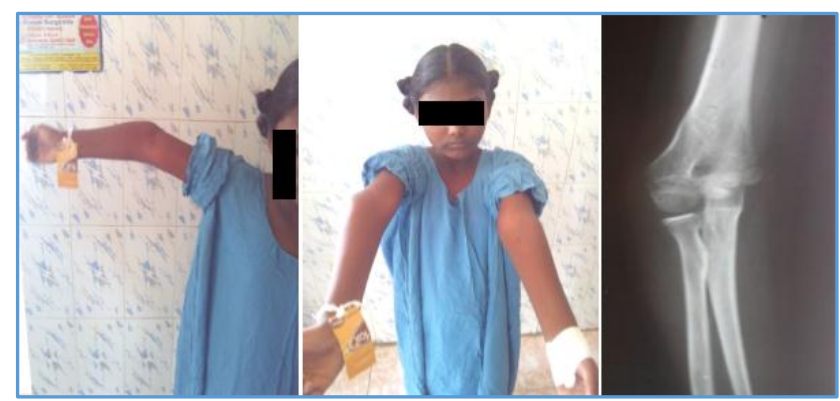




\section{Follow-Up}

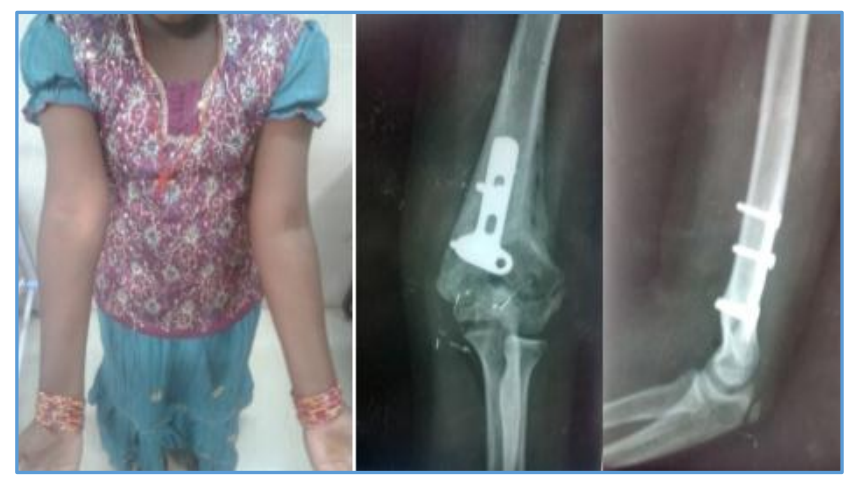

CASE 3

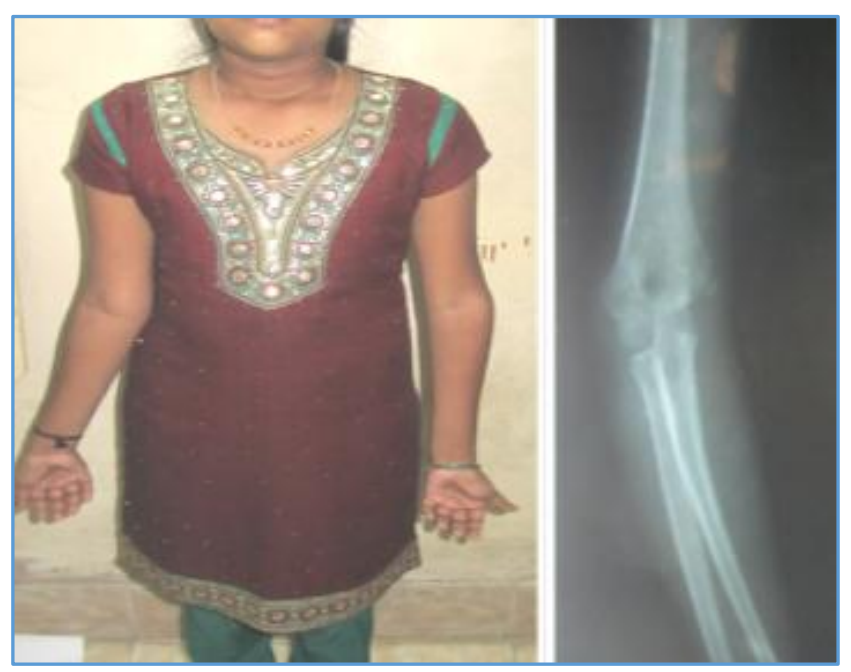

Follow-Up

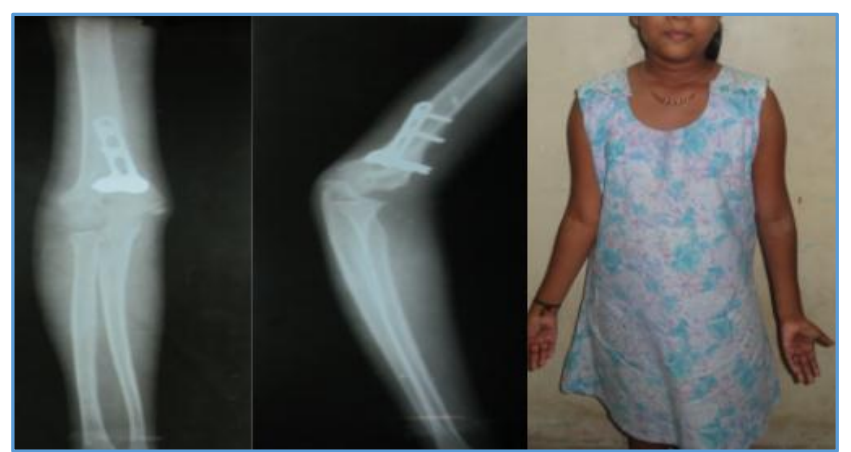

\section{DISCUSSION}

There are different techniques, different fixation to correct cubitus varus deformity, each has its own advantage and disadvantage.
Ippolito et al(3) in 1990 showed loss of correction due to growth, ulnar nerve palsy, decreased range of motion with Kwire fixation. Kim et al(4) used Y plate, all had good alignment and ROM. Yun et al(5) 22 cases had plates used, all had excellent results. MINY et al lateral wedge osteotomy is an efficient technique to correct cubitus varus deformity. Rang et al,(6) 20 cases treated with $\mathrm{K}$ wires, 3 had loss of position. Sweeney et al,(7) 14 patients were treated with $\mathrm{K}$ wires, 5 patients lost position. Bellmore et al(2) treated 13 patients with $\mathrm{K}$ wire, 4 had pin tract infection. Kumar $\mathrm{K}$ et al(8) revealed no significant difference in correction of carrying angle by both dome and French osteotomy. We had limitations in our study like small sample size, not a comparative study; however, results are promising. This method of correction is easy, stable with satisfactory results.

\section{CONCLUSION}

In our study, we conclude by saying that lateral closed wedge osteotomy and fixation with plate is a safe and effective technique with satisfactory results in cubitus varus deformity.

\section{REFERENCES}

[1] Oppenheim WL, Clader TJ, Smith C, et al. Supracondylar humeral osteotomy for traumatic childhood cubitus varus deformity. Clin Orthop Relat Res 1984;(188):34-9.

[2] Bellemore MC, Barrett IR, Middleton RW, et al. Supracondylar osteotomy of the humerus for correction of cubitus varus. J Bone Joint Surg [Br] 1984;66(4):566-72.

[3] Ippolito E, Moneta MR, D’Arrigo C. Post traumatic cubitus varus. Long term follow up of corrective supracondylar humeral osteotomy in children. J Bone Joint Surg Am 1990;72(5):757-62.

[4] Kim HS, Jahng JS, Han DY, et al. Modified step-cut osteotomy of the humerus. J Pediatric Orthop B 1998;7(2):162-6.

[5] Yun YH, Shin SJ, Moon JG. Reverse V osteotomy of the distal humerus for the correction of cubitus varus. J Bone Joint Surg Br 2007;89(4):527-31.

[6] Rang M. Children's fractures. Pheladilphia: JB Lippincot Co, 1974.

[7] Sweeney JG. Osteotomy of the humerus for malunion of supracondylar fracture. J Bone Joint Surg $\mathrm{Br}$ 1975;57:117.

[8] Kumar K, Sharma VK, Sharma R, et al. Correction of cubitus varus by French or dome oseotomy: a comparative study. J Trauma 2000;49(4):717-21. 